\title{
Publisher Correction: Delirium
}

Jo Ellen Wilson, Matthew F. Mart, Colm Cunningham, Yahya Shehabi, Timothy D. Girard, Alasdair M. J. MacLullich, Arjen J. C. Slooter and E. Wesley Ely

Nature Reviews Disease Primers (2020) https://doi.org/10.1038/s41572-020-00223-4 Published online 12 November 2020

The original version of the article contained an error in the annotation for reference 159. The HTML and PDF versions of the article have now been corrected to state that the MIND-USA trial found no effect of these antipsychotic drugs on days alive without delirium or coma, or duration of delirium or coma.

https://doi.org/10.1038/s41572-020-00236-z I Published online: 01 December 2020

(C) Springer Nature Limited 2020 